NASA/TM-2003-212510

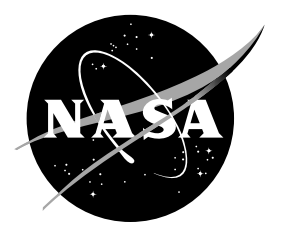

\title{
Magnetic Bearing Amplifier Output Power Filters for Flywheel Systems
}

Ramon C. Lebron-Velilla

Glenn Research Center, Cleveland, Ohio

Ralph H. Jansen

University of Toledo, Toledo, Ohio

Alan Palazzolo and Erwin Thomas

Texas A\&M University, College Station, Texas

Peter E. Kascak

University of Toledo, Toledo, Ohio

Arthur G. Birchenough

Glenn Research Center, Cleveland, Ohio

Timothy P. Dever

QSS Group, Inc., Cleveland, Ohio 
Since its founding, NASA has been dedicated to the advancement of aeronautics and space science. The NASA Scientific and Technical Information (STI) Program Office plays a key part in helping NASA maintain this important role.

The NASA STI Program Office is operated by Langley Research Center, the Lead Center for NASA's scientific and technical information. The NASA STI Program Office provides access to the NASA STI Database, the largest collection of aeronautical and space science STI in the world. The Program Office is also NASA's institutional mechanism for disseminating the results of its research and development activities. These results are published by NASA in the NASA STI Report Series, which includes the following report types:

- $\quad$ TECHNICAL PUBLICATION. Reports of completed research or a major significant phase of research that present the results of NASA programs and include extensive data or theoretical analysis. Includes compilations of significant scientific and technical data and information deemed to be of continuing reference value. NASA's counterpart of peerreviewed formal professional papers but has less stringent limitations on manuscript length and extent of graphic presentations.

- TECHNICAL MEMORANDUM. Scientific and technical findings that are preliminary or of specialized interest, e.g., quick release reports, working papers, and bibliographies that contain minimal annotation. Does not contain extensive analysis.

- CONTRACTOR REPORT. Scientific and technical findings by NASA-sponsored contractors and grantees.
- CONFERENCE PUBLICATION. Collected papers from scientific and technical conferences, symposia, seminars, or other meetings sponsored or cosponsored by NASA.

- SPECIAL PUBLICATION. Scientific, technical, or historical information from NASA programs, projects, and missions, often concerned with subjects having substantial public interest.

- TECHNICAL TRANSLATION. Englishlanguage translations of foreign scientific and technical material pertinent to NASA's mission.

Specialized services that complement the STI Program Office's diverse offerings include creating custom thesauri, building customized databases, organizing and publishing research results ... even providing videos.

For more information about the NASA STI Program Office, see the following:

- Access the NASA STI Program Home Page at http://www.sti.nasa.gov

- E-mail your question via the Internet to help@sti.nasa.gov

- Fax your question to the NASA Access Help Desk at 301-621-0134

- Telephone the NASA Access Help Desk at 301-621-0390

- Write to:

NASA Access Help Desk

NASA Center for AeroSpace Information 7121 Standard Drive

Hanover, MD 21076 
NASA/TM-2003-212510

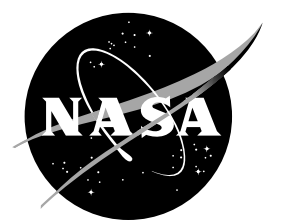

\section{Magnetic Bearing Amplifier Output Power Filters for Flywheel Systems}

Ramon C. Lebron-Velilla

Glenn Research Center, Cleveland, Ohio

Ralph H. Jansen

University of Toledo, Toledo, Ohio

Alan Palazzolo and Erwin Thomas

Texas A\&M University, College Station, Texas

Peter E. Kascak

University of Toledo, Toledo, Ohio

Arthur G. Birchenough

Glenn Research Center, Cleveland, Ohio

Timothy P. Dever

QSS Group, Inc., Cleveland, Ohio

Prepared for the

First International Energy Conversion Engineering Conference cosponsored by the American Institute of Aeronautics and Astronautics (AIAA), the American Society of Mechanical Engineers (ASME), and the Institute of Electrical and Electronics (IEEE)

Portsmouth, Virginia, August 17-21, 2003

National Aeronautics and

Space Administration

Glenn Research Center 
Available from

NASA Center for Aerospace Information 7121 Standard Drive

Hanover, MD 21076
National Technical Information Service 5285 Port Royal Road Springfield, VA 22100

Available electronically at http:/ /gltrs.grc.nasa.gov 


\section{MAGNETIC BEARING AMPLIFIER OUTPUT POWER FILTERS FOR FLYWHEEL SYSTEMS}

\author{
Ramon C. Lebron-Velilla \\ NASA Glenn Research Center \\ Cleveland, Ohio
}

Peter E. Kascak

University of Toledo

Toledo, Ohio

\author{
Ralph H. Jansen \\ University of Toledo \\ Toledo, Ohio
}

\author{
Alan Palazzolo \\ Texas A\&M University \\ College Station, Texas
}

\author{
Erwin Thomas \\ Texas A\&M University \\ College Station, Texas
}

\author{
Arthur G. Birchenough \\ NASA Glenn Research Center \\ Cleveland, Ohio
}

Timothy P. Dever
QSS Group, Inc.
Cleveland, Ohio

\begin{abstract}
Five power filters and two types of power amplifiers were tested for use with active magnetic bearings for flywheel applications. Filter topologies included low pass filters and low pass filters combined with trap filters at the PWM switching frequency. Two state and three state PWM amplifiers were compared. Each system was evaluated based on current magnitude at the switching frequency, voltage magnitude at $500 \mathrm{kHz}$, and power consumption. The base line system was a two state amplifier without a power filter. The recommended system is a three state power amplifier with a $50 \mathrm{kHz}$ low pass filter and a $27 \mathrm{kHz}$ trap filter. This system uses $5.57 \mathrm{~W}$. It reduces the switching current by an order of magnitude and the $500 \mathrm{kHz}$ voltage by two orders of magnitude. The relative power consumption varied depending on the test condition between $60 \%$ to $130 \%$ of the baseline.
\end{abstract}

\section{INTRODUCTION}

NASA Glenn Research Center has an ongoing effort in flywheel technology development and deployment for spacecraft applications [1]. Flywheel systems can be used to replace batteries for energy storage applications. Flywheel modules can also be deployed in an array which provides both energy storage and momentum control. This kind of system is called an Integrated Power and Attitude Control System (IPACS). A flywheel system consists of a number of flywheel modules and an electronics package which operates the motor/generators, the magnetic bearings, and the telemetry. The benefits of flywheel systems for energy storage applications are high energy density, high power density, long life, deep depth of discharge, and broad operating temperature ranges. In an IPACS configuration an additional mass savings can be achieved through the combination of the energy storage and the attitude control functions.

Flywheel modules for space use are designed to maximize energy density and minimize losses. Typically the energy storage component of the module is a rim composed of high strength carbon fiber. Energy is transferred to and from the wheel using a motor/generator. The flywheel module typically has some or all of these ancillary components: magnetic bearings, touchdown bearings, housing structure, sensors, connectors, and wiring harnesses. The flywheel modules used in this work all have a similar configuration (Figure 1). The rotating components are placed along a hub with the rim in the center of the hub. The motor, magnetic bearings, and touchdown bearings populate each end of the hub. The stationary parts of these components are located within the housing.

The flywheel modules used in this work have active magnetic bearings. An active magnetic bearing system utilizes a position feedback control system to levitate an object by adjusting a set of

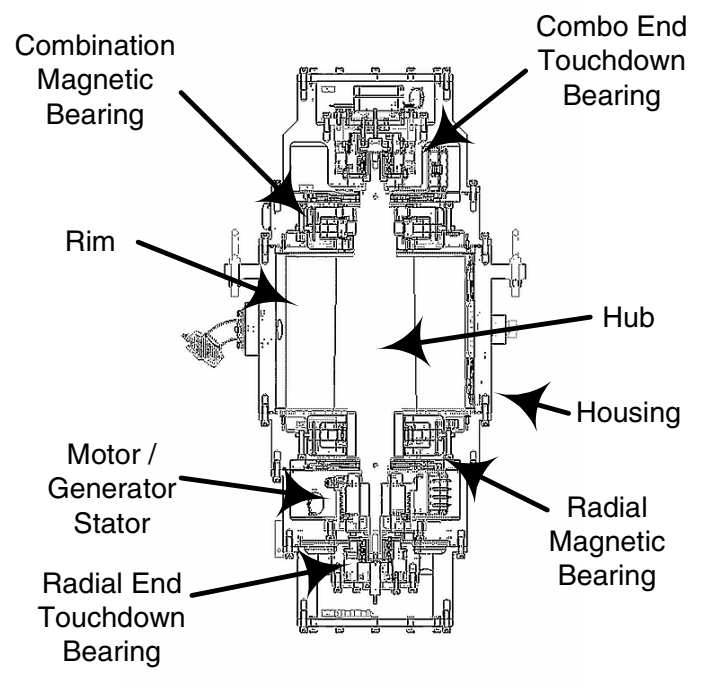

Figure 1-G2 Flywheel Module 


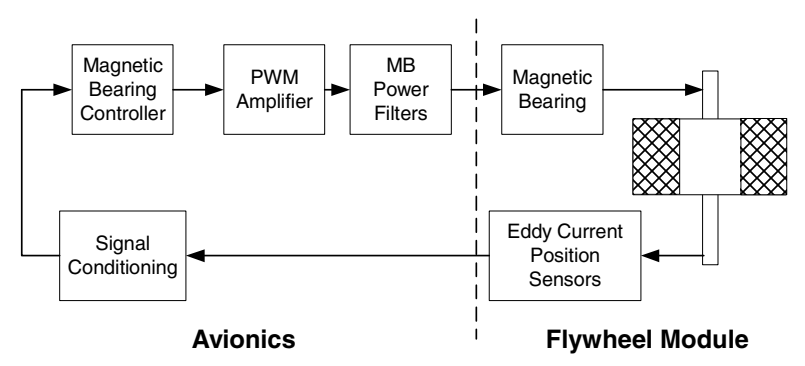

Figure 2 - Active Magnetic Bearing System

electromagnets (Figure 2). The flywheel modules have a five axis control system: two radial degrees of freedom at each end of the rotor and an axial degree of freedom. The magnetic bearing controller compares the desired rotor position to the actual and provides a current command to each of the power amplifiers. The power amplifiers track the current command within their bandwidth limit. The current flows through the magnetic bearing actuator producing magnetic fields in the air gaps between the bearing stator and rotor. In turn, the magnetic fields applied across the airgap produce a net force on the rotor. The rotor accelerates, changing its position. The sensors feed the position back as a signal level voltage. The voltage is scaled, offset, and filtered and sent to the magnetic bearing controller.

The necessary closed loop bandwidth of the magnetic bearing system depends on the flywheel module design. Our system bandwidth must be greater than $800 \mathrm{~Hz}$. The bandwidth typically is limited by the actuator and power amplifier. The controller bandwidth can be an issue if a complex algorithm is used which is difficult to execute in real time. Sensors and sensor conditioning becomes a problem if severe filtering must be applied.

\section{PROBLEM STATEMENT}

This paper addresses issues that arise with the use of switching power amplifiers for magnetic bearing systems. Switching power amplifiers are more compact and have lower losses than linear amplifiers. Two drawbacks of using them for magnetic bearings are interference with electromagnetic position sensors [2] and heating of the rotor system due to induced eddy currents.

To evaluate the impact of the power amplifier on the flywheel system it is convenient to consider the current and voltage applied to the magnetic actuator in the frequency domain (Figure 3). There are three frequency bands of interest. The first is the magnetic bearing control band from DC

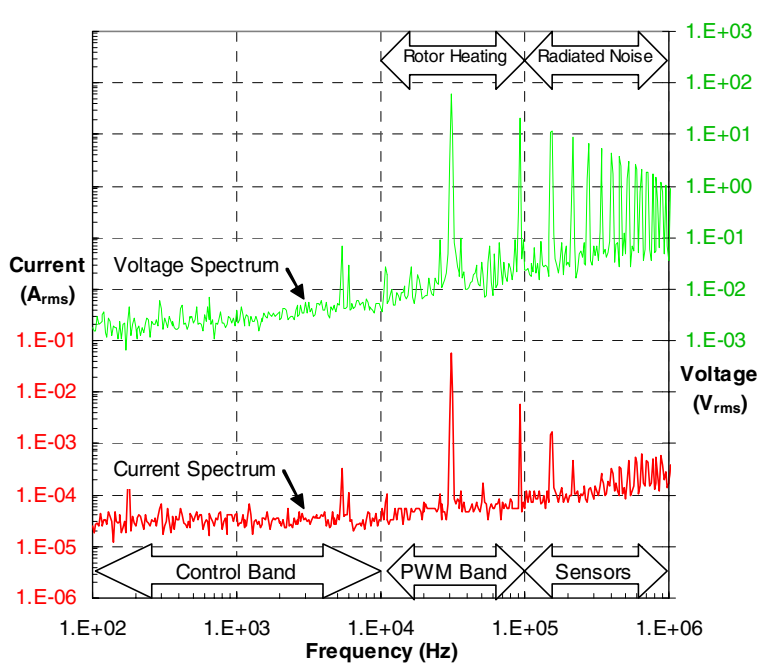

Figure 3 - Power Amplifier Spectrum

to $10 \mathrm{kHz}$. Within the magnetic bearing control band, the only currents and voltages applied should be a result of commands from the magnetic bearing controller. The second is the PWM switch frequency band from $10 \mathrm{kHz}$ to $100 \mathrm{kHz}$. The fundamental switching frequency of the power amplifier falls in this frequency range. The third is the sensor modulation frequency band from $100 \mathrm{kHz}$ to $1 \mathrm{MHz}$. When using eddy current sensors the carrier frequency is typically between $500 \mathrm{kHz}$ and $1 \mathrm{MHz}$.

The noise generated on the eddy-current position sensors results from radiated interference at the modulation frequency of the sensor. We utilize sensors with modulation frequencies of $500 \mathrm{kHz}$ and $1 \mathrm{MHz}$. Our discussion will be limited to the $500 \mathrm{kHz}$ sensors because they are utilized in the more sensitive control loops. Experimental data has shown that radiated PWM noise is picked up at the sensor head. The noise that occurs at the modulation frequency of $500 \mathrm{kHz}$ is demodulated in the eddy current sensor conditioning electronics, reducing its frequency into the control bandwidth of the magnetic bearing. Given that the control bandwidth is $10 \mathrm{kHz}$ implies that a low noise environment is required from $490-510 \mathrm{kHz}$. For example if a noise peak was present at $498 \mathrm{kHz}$ it would be demodulated to a $2 \mathrm{kHz}$ signal which would be well within the control bandwidth. The magnetic bearing feedback control would move the rotor in response to the noise.

Flywheel rotor heating is generated by eddy currents induced in the laminations of the magnetic bearing; this heating is generated by the switching frequency currents flowing in the magnetic bearing as well as control currents. 
Eddy currents are present in both the stator and rotor of the magnetic bearing actuator. The rotor heating presents a much more significant issue in a magnetically levitated system than stator heating because the only heat transfer path from the rotor is radiation.

\section{APPROACH}

Power filters were introduced between the PWM amplifiers and the magnetic bearing actuator in order to address the position sensor interference and rotor heating issues. The remainder of the paper compares different filter designs.

Two filter topologies were studied. The first was a low pass filter. Three different corner frequencies were evaluated. The corner frequencies were 50,100, and $400 \mathrm{kHz}$. The second topology is a low pass filter coupled with a trap filter at the switching frequency of the power amplifier. Two filters of this type were tested with low pass corner frequencies of 50 and $100 \mathrm{kHz}$. The trap frequency was $27 \mathrm{kHz}$ in each case.

Filters were evaluated by driving them with two types of PWM amplifiers using an air core inductor to simulate the actuator. Spectra of the current and voltage at the load inductor were measured between $100 \mathrm{~Hz}$ and $1 \mathrm{MHz}$. Voltage transfer functions between the input and output of the filter were used to verify the filter topology. Transfer functions between amplifier command and current at the load inductor were used to characterize the impact on the magnetic bearing control bandwidth. Finally the DC power consumption was measured in each configuration. The power consumption of the filters was calculated by subtracting the power with the filter from the power without a filter.

Testing was conducted under two simulated magnetic bearing commands. The first was a zero input condition akin to a levitated rotor at the current zero point. The second command was a one amp, $1 \mathrm{kHz}$ signal meant to simulate a rotating flywheel. This is several times the amplitude that is required to levitate a flywheel rotor at 60,000 RPM spin speed.

\section{RESULTS}

The first phase of testing was verification that the filters performed as designed. Each filter voltage input to voltage output transfer function was measured between $1 \mathrm{kHz}$ and $1 \mathrm{MHz}$ (Figure 4) The gain roll off of the three lowpass

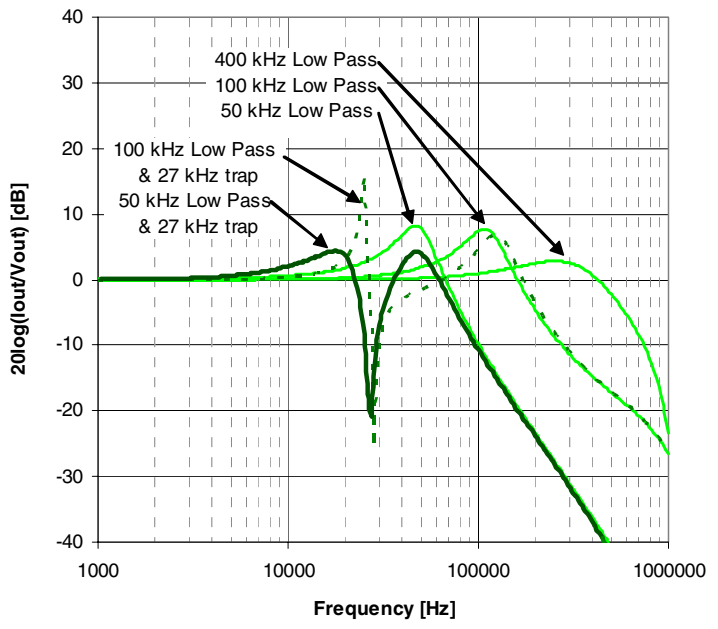

Figure 4 - Voltage out / Voltage in Filter Transfer Functions.

filters can be seen cascading down from the right side of the graph as the corner frequency is reduced from $400 \mathrm{kHz}$ to $100 \mathrm{kHz}$ and finally to $50 \mathrm{kHz}$. The transfer functions of the two filters which have traps are seen with attenuation at $27 \mathrm{kHz}$. The $100 \mathrm{kHz}$ lowpass and $27 \mathrm{kHz}$ trap (dashed line) has a significant overshoot region below the trap frequency, with approximately $25 \mathrm{~dB}$ attenuation at the trap frequency. The $50 \mathrm{kHz}$ lowpass filter and $27 \mathrm{k} \mathrm{Hz}$ trap shows some overshoot on both sides of the trap frequency with approximately $20 \mathrm{~dB}$ attenuation. Both filters converge to their respective low pass filter transfer functions at high frequency.

Current, voltage, and power measurements were made after the filter topologies were verified. Figure 5 summarizes these results. The first lower bar graph is a logarithmic plot of the magnitude of

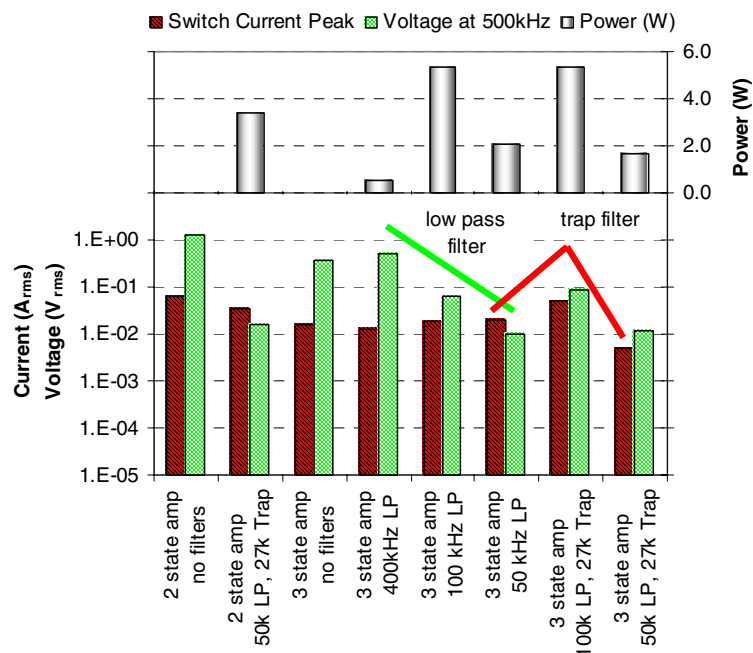

Figure 5 - Filter and Amplifier performance summary 
the current at the PWM switching frequency, which was used as an indicator of eddy current heating. The second lower bar graph is the logarithmic magnitude of the voltage at $500 \mathrm{kHz}$ which is used as an indicator of the interference level with the position sensors. The top set of bars is the power consumption of each filter. This was calculated by subtracting the filtered from the unfiltered power consumption.

A few trends emerge from this data. The first is that adding a trap filter reduces the currents at the switch frequency. This can be seen by comparing the 3 state amplifier, $50 \mathrm{kHz}$ low pass data with and without the trap filter. The trap filter does not have the same benefit with the $100 \mathrm{kHz}$ filter. This result is misleading because the trap filter resonates with the particular $100 \mathrm{kHz}$ filter implementation used for this experiment (Figure 4). Another trend is the reduction of high frequency noise as the low pass filter frequency is reduced. This is illustrated in the 3 state amplifier data with the 400,100 , and $50 \mathrm{kHz}$ low pass filters. Trends in the filter power consumption data are less clear because the specific implementations of the filters were done somewhat differently. Clearly some power will be used in the filter; however reduced magnetic bearing noise may balance some of the losses. Additional work will be done to determine the net power use in a flywheel module application.

\section{PWM Amplifier Switching Methods}

Two types of magnetic bearing Pulse Width Modulation (PWM) amplifiers were tested in order to determine which one generated the lower amount of noise at the switching frequency of $27 \mathrm{kHz}$. The two types of amplifiers have an identical full bridge power stage topology (Figure 6). The difference lies in their switching scheme. The first type is a 2 state amplifier, where the conduction of positive or negative current is controlled by controlling the duty cycle of the positive and negative "leg" of the full bridge.

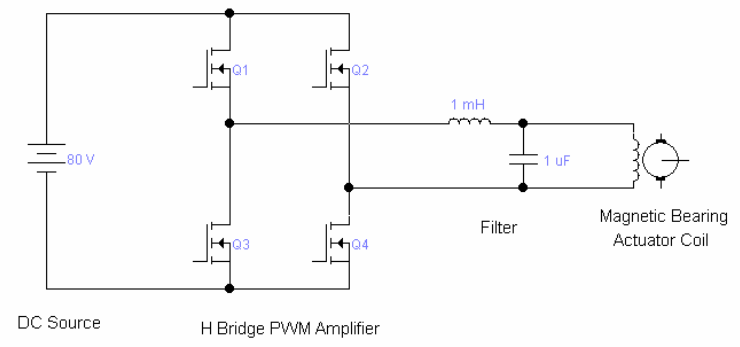

Figure 6 - PWM amplifier and filter topology
In this operating regime, the amplifier will generate a voltage that switches to the positive and negative source rail during each switching cycle. This holds true even when the current command is 0 Amps. The objective of continuous switching, even at zero amps, is to make the transition from positive current to negative current as smooth as possible. The second type of amplifier is the three-state switching, where the control of positive current is performed by switching the amplifier positive leg only and the control of negative current is performed by switching the negative leg only. In this regime, the amplifier will generate a voltage that switches between zero and positive source rail for positive current, or between zero and negative source rail for negative current. The advantage of this switching scheme is that there is no switching (all the bridge switches are OFF) when the current command is zero. From the system noise perspective, this is very attractive since the zero current point is the typical operating scenario for a levitated rotor under balanced conditions.

Figure 7 compares the two amplifiers output current spectra when the current command is zero amps and the amplifiers output terminals are connected to an air core inductor. The air core inductance value is $6.8 \mathrm{mH}$, an inductance value similar to the inductance of the magnetic bearing actuator coil. The amplifiers were tested without a filter. Clearly, the two-state amplifier shows a dominant frequency component at the switching frequency of $27 \mathrm{kHz}$ and higher order harmonics. This component is absent or significantly reduced in the spectrum of the three-state amplifier that is also switching at $27 \mathrm{kHz}$.

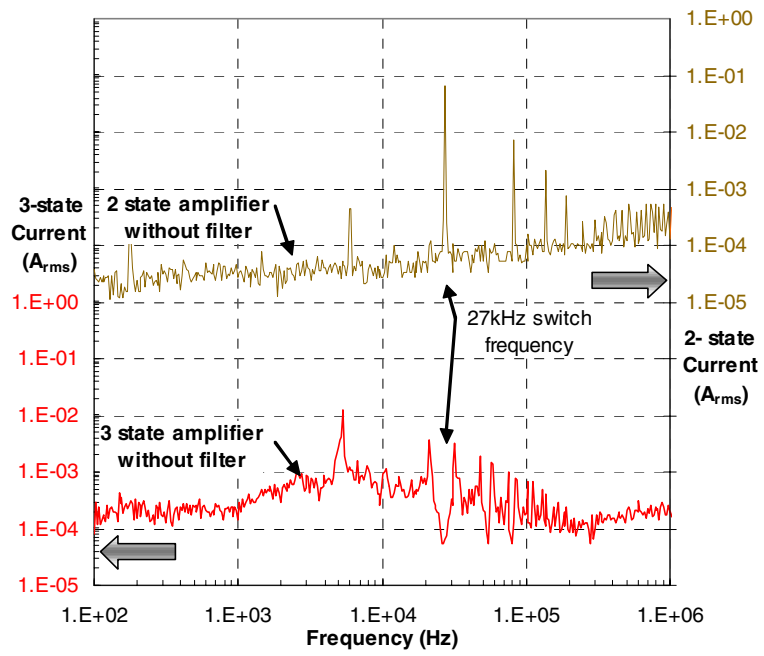

Figure 7 - Two-state vs. Three-state PWM amplifier Current Spectrum with Zero Amps command (No filter) 
Voltage Spectra for the two amplifiers operating under the same conditions are shown in Figure 8. The upper chart line in Figure 8 shows that the two-state amplifier voltage spectra contain approximately $50 \mathrm{~V}_{\mathrm{rms}}$ component at $27 \mathrm{kHz}$. The spectrum also shows noisy behavior in the range from $100 \mathrm{kHz}$ to $1 \mathrm{MHz}$. In contrast, the lower chart line in Figure 8 shows the three-state amplifier voltage spectrum where the component at $27 \mathrm{kHz}$ is well below the $5 \mathrm{~V}_{\text {rms }}$ mark. The

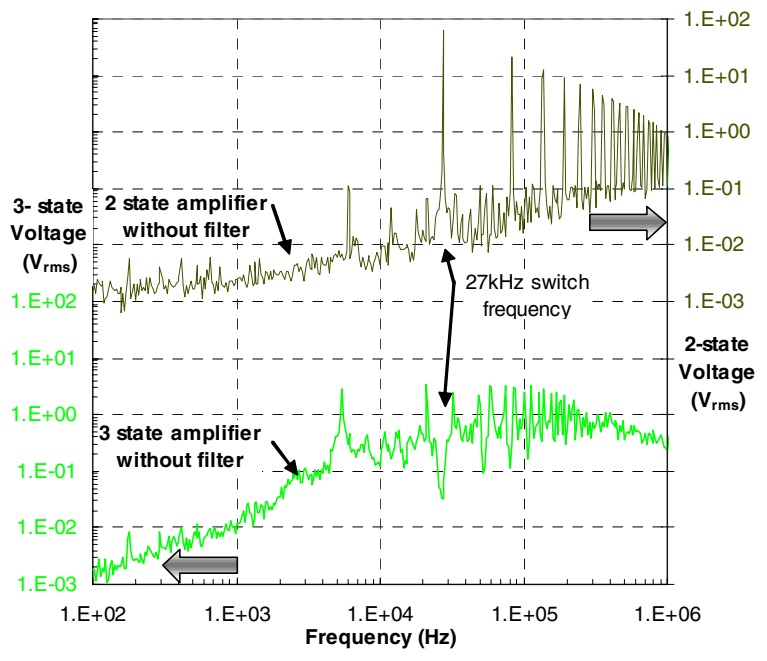

Figure 8 - Two-state vs. Three-state PWM amplifier Voltage Spectrum with Zero Amps command (No filter)

measured noise in the frequency range between $100 \mathrm{kHz}$ and $1 \mathrm{MHz}$ is also considerably lower, reaching levels lower than the $0.5 \mathrm{~V}_{\text {rms }}$ mark at $1 \mathrm{MHz}$. In terms of power consumption, tests revealed that input power into the two types of PWM amplifiers was significantly different at zero current command. The three-state amplifier showed an input power consumption of $1.73 \mathrm{~W}$, for the zero amp command, and 3.93W for the 1 amp peak-to-peak current command test condition. On the other hand, the two-state amplifier showed a power consumption of $3.31 \mathrm{~W}$, for the zero amp command, and $4.32 \mathrm{~W}$ for $1 \mathrm{amp}$ peak-to-peak current command test condition. Therefore, as expected, the three-state amplifier requires less input power for a zero current command because there is no switching action at this operating condition. The power difference is not as dramatic for the 1 amp peak-to-peak current command because, at this operating point, both amplifiers will be switching.
Performance of the Selected Combination of filter and PWM Amplifier

Combinations of amplifiers and filters were tested to find the best combination of low power use, small switch frequency currents, and low noise at the position sensor frequency of $500 \mathrm{kHz}$.

Figure 5 compares the results of the current and voltage frequency content measurements and also compares the power losses for the different amplifier and filter combinations tested. Careful examination of these results reveals that the best option in terms of filter performance and power consumption is the three-state PWM amplifier in combination with the $50 \mathrm{kHz}$ low pass filter and the $27 \mathrm{kHz}$ trap filter. This combination has the lowest switch frequency current component and second lowest $500 \mathrm{kHz}$ voltage component with low power consumption.

Figure 9 shows the schematic diagram of the selected filter. The $700 \mathrm{uH}$ inductor and the $0.047 \mathrm{uF}$ capacitor provide the $27 \mathrm{kHz}$ trap or band reject filter, and the $1 \mathrm{mH}$ inductor and the $0.01 \mathrm{uF}$ capacitor provide the $50 \mathrm{kHz}$ low pass filter. The $390 \mathrm{ohm}$ resistor and $0.033 \mathrm{uF}$ capacitor provided damping.

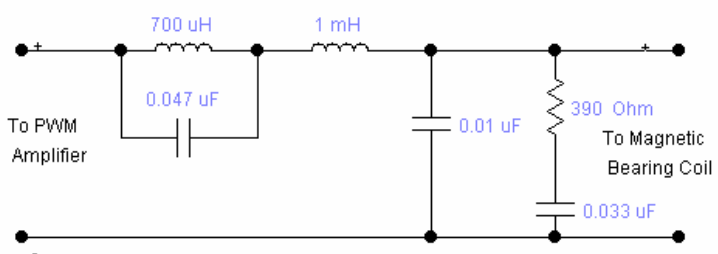

Figure 9 - Circuit schematic of selected $27 \mathrm{kHz}$ trap and $50 \mathrm{kHz}$ Low Pass filter

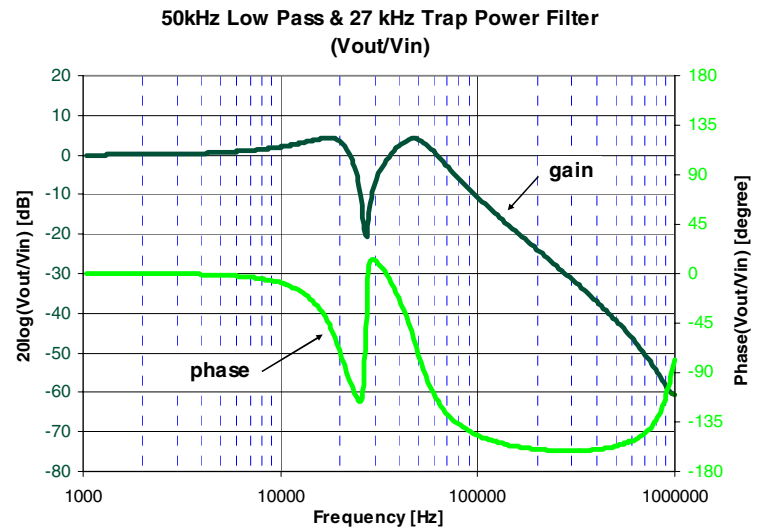

Figure 10 - Measured Transfer Function for Selected Filter $\left[20^{*} \log \left(\mathrm{V}_{\text {out }} / \mathrm{V}_{\text {in }}\right)\right]$ in decibels and degrees 
Figure 10 shows the tested voltage transfer function of this filter. For our tests, the trap filter was finely tuned to provide maximum attenuation at precisely $27 \mathrm{kHz}$. Similarly, the PWM amplifiers were synchronized with an external oscillator to operate with a switching frequency of exactly $27 \mathrm{kHz}$.

Figure 11 shows the comparison of the current spectra between the unfiltered two-state PWM amplifier and the synchronized three-state amplifier with the $27 \mathrm{kHz}$ Trap and the $50 \mathrm{kHz}$ low pass filter. The current command for this condition was 0 amps. The spectra show that the combination of the three-state amplifier and the selected filter is very effective in reducing the switching frequency noise in the current flowing in the magnetic bearing coils.

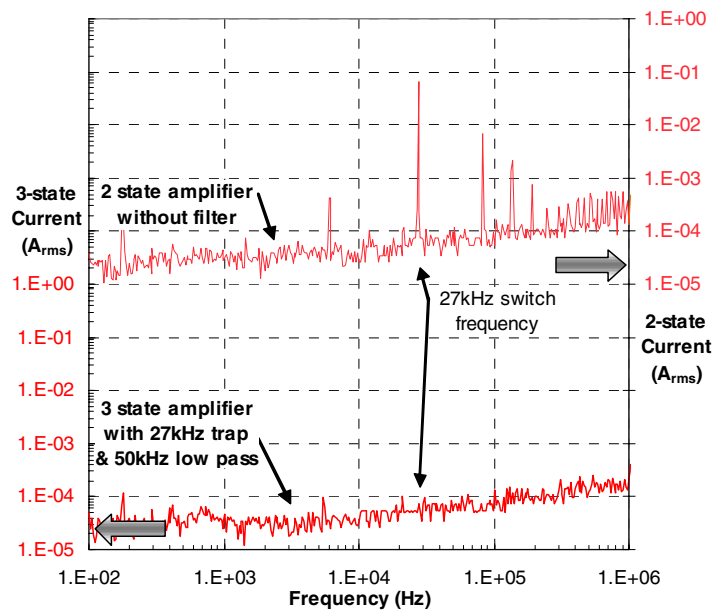

Figure 11 - Current Spectrum of Two-state amplifier with No filter vs. Three-state amplifier with $27 \mathrm{kHz}$ trap and $50 \mathrm{kHz}$ low pass filter with Zero Amps command

Figure 12 also shows a drastic reduction of switching noise in the voltage from the PWM amplifiers at 0 amp command. This reduction is evident in both the switching frequency and also in the frequency range from $100 \mathrm{kHz}$ to $1 \mathrm{MHz}$. Low noise in the frequency range around $500 \mathrm{kHz}$, as explained previously, is extremely important to reduce the radiated emissions that can be picked up by the magnetic bearing position sensors.

Figure 13 shows the current spectra when the current command into the PWM amplifiers is 1 amp peak to peak with a frequency of $1 \mathrm{kHz}$. This command frequency is well under the control bandwidth of the PWM amplifier, and well under the effect of the trap and low pass filter as can be observed in Figure 10 and Figure 15. The $1 \mathrm{Amp}$ peak-to-peak command is intended to simulate

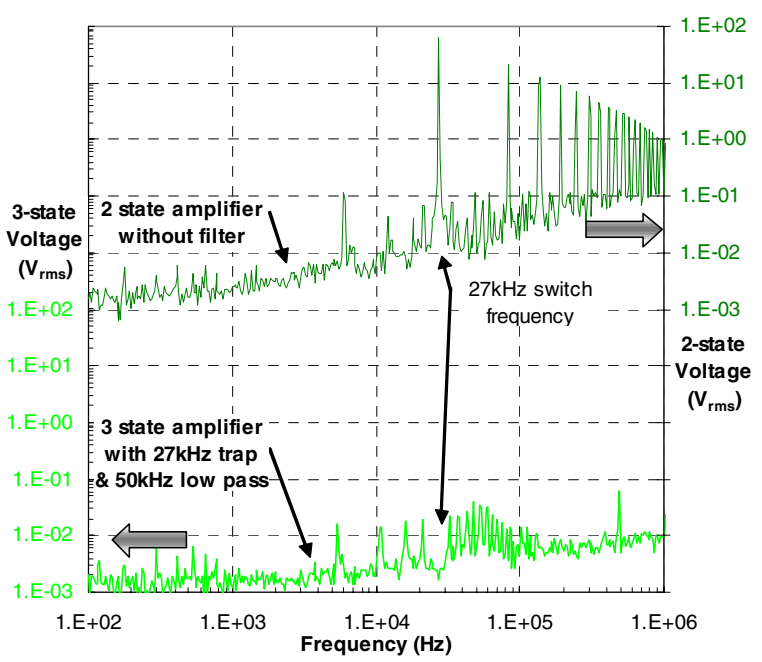

Figure 12 - Voltage Spectrum of Two-state amplifier with No filter vs. Three-state amplifier with $27 \mathrm{kHz}$ trap and $50 \mathrm{kHz}$ low pass filter with Zero Amps command

the load that the amplifiers supply when levitating a rotating flywheel. The current spectra show the large component that corresponds to the $1 \mathrm{kHz}$ command. Examination of the current spectra for the two configurations reveals a significant reduction in the $27 \mathrm{kHz}$ noise measured in the current of filtered three-state amplifier.

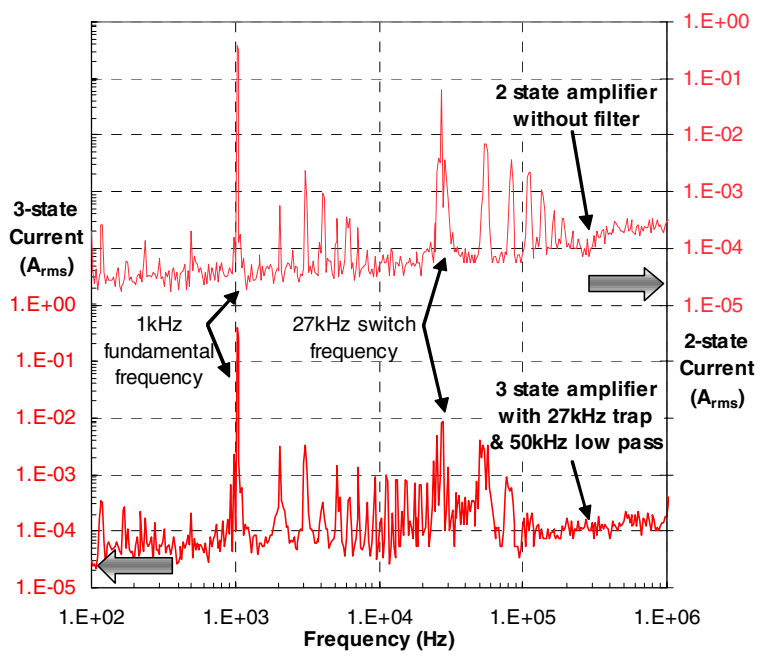

Figure 13 - Current Spectrum of Two-state amplifier with No filter vs. Three-state amplifier with $27 \mathrm{kHz}$ trap and $50 \mathrm{kHz}$ low pass filter with $1 \mathrm{kHz}, 1$ Amp p-p command

The voltage spectra for these two configurations in Figure 14 reveal not only a reduction in the $27 \mathrm{kHz}$ noise from the switching action, but also a considerable reduction in the 


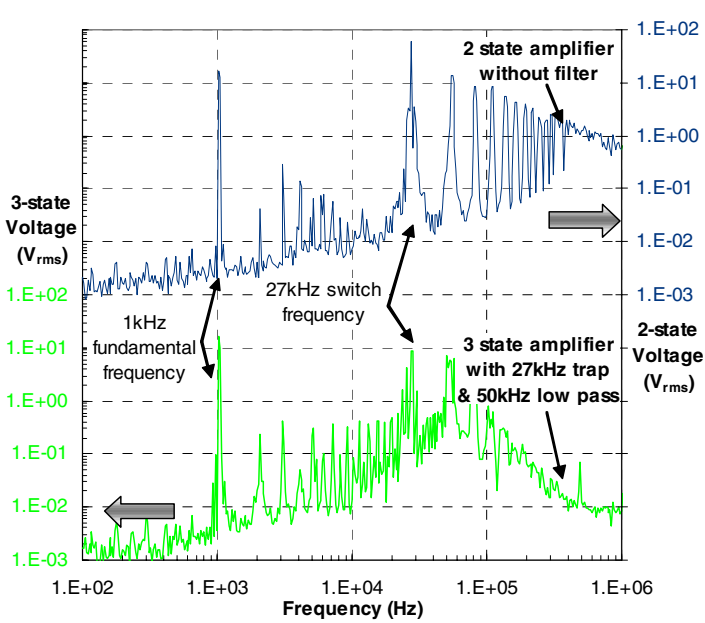

Figure 14 - Voltage Spectrum of Two-state amplifier with No filter vs. Three-state amplifier with $27 \mathrm{kHz}$ trap and $50 \mathrm{kHz}$ low pass filter with $1 \mathrm{kHz}, 1$ Amp p-p command

noise floor in the frequency range from $100 \mathrm{kHz}$ to $1 \mathrm{MHz}$. This is logically the effect of the $50 \mathrm{kHz}$ low pass filter.

Transfer function Bode plots were generated by test in order to characterize the frequency response of the PWM amplifiers with and without filters. The objective was to verify that the use of the filter does not reduce the PWM amplifier control bandwidth below $1 \mathrm{kHz}$, and also to verify that the filter does not introduce a phase lag higher than 45 degrees below $1 \mathrm{kHz}$. Figure 15 shows Bode plots for the two-state amplifier with no filter and the three-state amplifier with the $27 \mathrm{kHz}$ trap and the $50 \mathrm{kHz}$ low pass filter. The

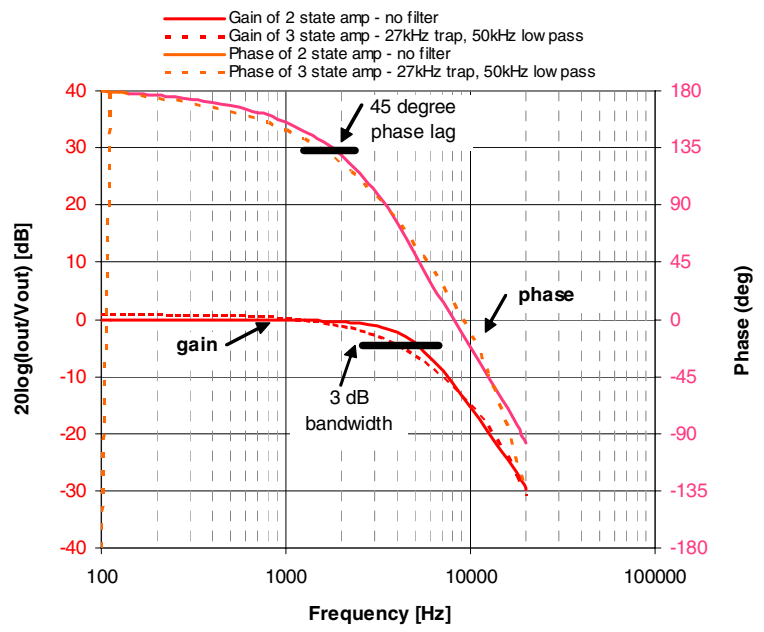

Figure 15 - lout/Vcommand Transfer Function of Two-state amplifier with No filter vs. Three-state amplifier with $27 \mathrm{kHz}$ trap and $50 \mathrm{kHz}$ low pass filter with 1 Amp p-p command upper chart line Figure 15 shows the phase response while the lower chart line shows the gain. The filter reduces the gain bandwidth from $5 \mathrm{kHz}$ to approximately $4 \mathrm{kHz}$, and the 45 degree phase lag point is still greater than $1 \mathrm{kHz}$. The transfer function was generated with the ratio of the command signal voltage and the amplifier output current. The formula is [ $\left.20 \log \left(\mathrm{V}_{\text {com }} / \mathrm{I}_{\text {out }}\right)\right]$. These Bode plot tests clearly demonstrate that the control bandwidth requirements for the magnetic bearing actuators are still met with the three-state amplifier and the selected filter.

\begin{tabular}{|l|c|c|}
\hline Command & $\begin{array}{c}\text { Two-State Amp } \\
\text { No Filter }\end{array}$ & $\begin{array}{c}\text { Three-State Amp and } \\
27 \mathrm{kHz} \text { Trap and } \\
50 \mathrm{kHz} \text { Low Pass } \\
\text { Filter }\end{array}$ \\
\hline 0 Amps & $3.31 \mathrm{~W}$ & $1.90 \mathrm{~W}$ \\
\hline $1 \mathrm{Amp} p-\mathrm{p}$ & $4.32 \mathrm{~W}$ & $5.57 \mathrm{~W}$ \\
\hline
\end{tabular}

Table 1. Power Consumption Comparison of Two-

State Amplifier with No filter, and the three-state amplifier with Low Pass and Trap Filter

In terms of power consumption, Table 1 considers the power consumption of the two-state amplifier with no filter, and the power consumption of the three-state amplifier with low pass and trap filter. As expected, the zero amp current command requires lower power when the threestate amplifier is used. On the other hand, the filter represents a power penalty when the amplifiers are operating with a 1 amp peak to peak current command. The rationale for selection of the filtered three-state amplifier lies in the fact that the zero amp command condition is more typical and characteristic of the steady state operating scenario for the magnetic bearing with a balanced flywheel. Under these circumstances, the filter power penalty can be accepted for transient nonzero current command conditions.

\section{CONCLUSIONS}

Several power filter and amplifier combinations were evaluated to determine the best topology for an active magnetic bearings system for flywheels. Each system was evaluated based on current magnitude at the switching frequency, voltage magnitude at $500 \mathrm{kHz}$, and power consumption. Test data was taken at two conditions, zero amps commanded and $1 \mathrm{amp}$ at $1 \mathrm{kHz}$ commanded.

Several observations were made. The three state amplifier had reduced switching currents, high frequency noise, and power consumption compared to the two state amplifier. Addition of 
low pass filters reduces high frequency noise. Adding a trap filter reduces the magnitude of switching frequency current. The addition of the filters uses some power.

The base line system was a two state amplifier without a power filter. The recommended system is a three state power amplifier with a $50 \mathrm{kHz}$ low pass filter and a $27 \mathrm{kHz}$ trap filter. This system consumed $1.90 \mathrm{~W}$ which is $60 \%$ of the energy of the base line system under the zero amp command. Under a $1 \mathrm{~A}, 1 \mathrm{kHz}$ command the recommended system consumed $5.57 \mathrm{~W}$ which is $130 \%$ of the baseline. Since typical operation is closer to the zero amp condition, the recommended system will reduce average power use. The baseline system has a switching current magnitude of $62.9 \mathrm{~mA}$ compared to $4.9 \mathrm{~mA}$ for the recommend system under a $1 \mathrm{~A}, 1 \mathrm{kHz}$ command. With the same test conditions the baseline system has $1.25 \mathrm{~V}$ of noise at $500 \mathrm{kHz}$ compared to $0.012 \mathrm{~V}$ for the recommended system.

Changing from the base line to the recommend system will reduce the switching current by an order of magnitude, the $500 \mathrm{kHz}$ voltage by two orders of magnitude, and the average power consumption. The flywheel system will be more efficient, cooler operating, and more stable as a result.

\section{REFERENCES}

[1] McLallin, K., Jansen, R., Fausz, J., Bauer, R., "Aerospace Flywheel Technology Development for IPACS Applications," NASA/TM2001-211093, October 2001.

[2] Dever, T. P., Palazzolo, A. B., Thomas, E. M., and Jansen, $R$. H., "Evaluation and Improvement of Eddy Current Position Sensors in Magnetically Suspended Flywheel Systems," July 2001 IECEC Conference Proceedings, Savannah, Georgia, 2001. 
Public reporting burden for this collection of information is estimated to average 1 hour per response, including the time for reviewing instructions, searching existing data sources, gathering and maintaining the data needed, and completing and reviewing the collection of information. Send comments regarding this burden estimate or any other aspect of this collection of information, including suggestions for reducing this burden, to Washington Headquarters Services, Directorate for Information Operations and Reports, 1215 Jefferson Davis Highway, Suite 1204, Arlington, VA 22202-4302, and to the Office of Management and Budget, Paperwork Reduction Project (0704-0188), Washington, DC 20503.

\begin{tabular}{|l|l|l}
\hline 1. AGENCY USE ONLY (Leave blank) & $\begin{array}{c}\text { 2. REPORT DATE } \\
\text { August } 2003\end{array}$ & $\begin{array}{r}\text { 3. REPORT TYPE AND DATES COVERED } \\
\text { Technical Memorandum }\end{array}$ \\
\hline
\end{tabular}

4. TITLE AND SUBTITLE 5. FUNDING NUMBERS

Magnetic Bearing Amplifier Output Power Filters for Flywheel Systems

\section{AUTHOR(S)}

WBS-22-755-60-15

Ramon C. Lebron-Velilla, Ralph H. Jansen, Alan Palazzolo, Erwin Thomas,

Peter E. Kascak, Arthur G. Birchenough, and Timothy P. Dever

\section{PERFORMING ORGANIZATION NAME(S) AND ADDRESS(ES)}

National Aeronautics and Space Administration

John H. Glenn Research Center at Lewis Field

Cleveland, Ohio 44135-3191

8. PERFORMING ORGANIZATION REPORT NUMBER

E-14070

\section{SPONSORING/MONITORING AGENCY NAME(S) AND ADDRESS(ES)}

National Aeronautics and Space Administration

Washington, DC 20546-0001

10. SPONSORING/MONITORING AGENCY REPORT NUMBER

NASA TM-2003-212510

\section{SUPPLEMENTARY NOTES}

Prepared for the First International Energy Conversion Engineering Conference cosponsored by the American Institute of Aeronautics and Astronautics (AIAA), the American Society of Mechanical Engineers (ASME), and the Institute of Electrical and Electronics (IEEE), Portsmouth, Virginia, August 17-21, 2003. Ramon C. Lebron-Velilla and Arthur G. Birchenough, NASA Glenn Research Center; Ralph H. Jansen and Peter E. Kascak, University of Toledo, Toledo, Ohio 43606; Alan Palazzolo and Erwin Thomas, Texas A\&M University, College Station, Texas 77843; and Timothy P. Dever, QSS Group, Inc., Cleveland, Ohio 44135. Responsible person, Ramon C. Lebron-Velilla, organization code 5450, 216-433-6482.

12a. DISTRIBUTION/AVAILABILITY STATEMENT 12b. DISTRIBUTION CODE

Unclassified - Unlimited

Subject Categories: 20, 33, 37, and 44

Distribution: Nonstandard

Available electronically at http://gltrs.grc.nasa.gov

This publication is available from the NASA Center for AeroSpace Information, 301-621-0390.

\section{ABSTRACT (Maximum 200 words)}

Five power filters and two types of power amplifiers were tested for use with active magnetic bearings for flywheel applications. Filter topologies included low pass filters and low pass filters combined with trap filters at the PWM switching frequency. Two state and three state PWM amplifiers were compared. Each system was evaluated based on current magnitude at the switching frequency, voltage magnitude at $500 \mathrm{kHz}$, and power consumption. The base line system was a two state amplifier without a power filter. The recommended system is a three state power amplifier with a $50 \mathrm{kHz}$ low pass filter and a $27 \mathrm{kHz}$ trap filter. This system uses $5.57 \mathrm{~W}$. It reduces the switching current by an order of magnitude and the $500 \mathrm{kHz}$ voltage by two orders of magnitude. The relative power consumption varied depending on the test condition between 60 to 130 percent of the baseline.

\begin{tabular}{|c|c|c|}
\hline \multicolumn{3}{|l|}{$\begin{array}{l}\text { 14. SUBJECT TERMS } \\
\text { Magnetic bearings; Pov } \\
\text { Low pass filters }\end{array}$} \\
\hline $\begin{array}{l}\text { 17. SECURITY CLASSIFICATION } \\
\text { OF REPORT }\end{array}$ & $\begin{array}{l}\text { 18. SECURITY CLASSIFICATION } \\
\text { OF THIS PAGE }\end{array}$ & $\begin{array}{l}\text { 19. SECURITY CLASSIFICATION } \\
\text { OF ABSTRACT }\end{array}$ \\
\hline & & Unclassified \\
\hline
\end{tabular}

